\title{
Reseña
}

\section{La tercera edad se hace visible}

\section{Ana Ávila Bohórquez}

DOI: $10.5294 /$ pacla.2021.24.4.7

Para citar esta reseña / To cite this book review / Para citar esta resenha

Ávila, A. (2021). La tercera edad se hace visible. Palabra Clave, 24(4), e2447. D0I: https:// doi.org/10.5294/pacla.2021.24.4.7

Reseña del libro:

Guarinos, V. (coord.) (2021). La isla etaria: tercera edad y medios de comunicación. Sevilla: ReaDuck.

El edadismo es la estereotipación y discriminación contra personas o colectivos por motivos de edad. Engloba una serie de creencias, normas y valores que justifican la discriminación de las personas según los años de vida, en especial si son muchos. En el grupo de investigación Admira, de la Universidad de Sevilla, se centran en este colectivo muy maltratado en su representación en los medios, el de los envejecientes, como lo han venido haciendo con el resto de categorías de la diferencia. El objetivo central de este libro es el de desmontar, sobre todo, dos imágenes estereotipadas del anciano. Por un lado, la del anciano como persona limitada y frágil, a menudo retratada con paternalismo. Por el otro, la negación de la edad, representando a personas envejecientes como si fueran jóvenes saludables y activos. Así, esta obra colectiva pretende aportar una visión más cercana a la realidad de las personas de la tercera edad.

Para ello, varios capítulos aportan datos estadísticos sobre el colectivo de envejecientes: desde su peso específico como consumidores de medios, datos sobre el envejecimiento de la población, el número de persona mayores de 55 años que juegan videojuegos o el grado de conocimien-

$1 \bowtie$ https://orcid.org/0000-0002-9783-8648. Universidad Complutense de Madrid, España. aavila04@ucm.es 
to tecnológico de este sector de la población. Estos datos acompañan el análisis de la representación de los ancianos en diversos medios y la descripción de su papel en discursos mediáticos.

El volumen está dividido en diez partes y prologado por Francisco A. Zurian, director del Grupo de Investigación "Género, estética y cultura audiovisual (GECA)" de la Universidad Complutense de Madrid. El primer capítulo, escrito por Virginia Guarinos, directora del grupo de investigación Admira, realiza una explicación del edadismo y un repaso general de las imágenes de envejecientes en los medios. Así, este primer capítulo sirve a su vez de introducción y contexto para el resto del libro. Además, es el único artículo dedicado a la radio, el medio que quizás más se asocie con la tercera edad.

El resto de capítulos abarcan todos los demás medios de comunicación: el cine, la televisión de ficción y la televisión de entretenimiento, las redes sociales, la publicidad y la representación de la tercera edad en la prensa especializada en videojuegos. El libro muestra el papel de los envejecientes como consumidores de todos estos medios, pero solo los retrata como productores de contenido en lo que se refiere a la radio y las redes sociales, acaso por ser estos dos medios los más accesibles con unos conocimientos técnicos más de aficionado.

A lo largo de sus diez capítulos, el texto recalca la idea de la falta de interés de los medios comerciales por la ancianidad. Solo las radios universitarias y locales parecen incluir programas hechos por y para la tercera edad, y los autores defienden que solo el cine de autor muestra personajes envejecientes alejados de los estereotipos. Sin embargo, el increíble aumento del contenido televisivo de ficción y el gran número de plataformas han llevado a la diversificación de historias y personajes, en busca de nuevos nichos de mercado.

En su búsqueda por romper estereotipos respecto a la representación de la tercera edad en los medios, son varios los capítulos que se ocupan del sexo en la ancianidad. El capítulo 8, escrito por Irene Liberia Vayá y Sergio Cobo Durán, se centra en la representación de la sexualidad de los enveje- 
cientes en el cine del siglo XXI. Asimismo, encontramos este tema también en el epígrafe dedicado a la película La juventud (Paolo Sorrentino, 2015), escrito por Valerio Durán Manso, y, en su vertiente femenina, en el análisis de la serie Grace y Frankie (Netflix: 2015-2021). También se habla de sexualidad femenina en la tercera edad en el artículo sobre la "Yaya's Week" de La Resistencia (\#0: 2018-presente).

Este interés por la sexualidad de las mujeres envejecientes está relacionado con otro de los temas clave del libro: la asimilación de juventud con belleza, lo que conlleva una doble discriminación para las mujeres. "La arruga es bella" parece ser el lema de los capítulos dedicados a las "abuelas instagrammers", capítulo 5, escrito por Inmaculada Gordillo y Sergio Toledo, y el centrado en la película $O$ que arde (Oliver Laxe, 2019). No obstante, la sección que más se centra en la correlación entre belleza y senectud es el capítulo 6, escrito por Inmaculada Sánchez-Labella Martín, donde se realiza un análisis del uso del cuerpo en publicidad de moda y cosméticos.

Otro de los temas transversales del compendio es la relación de la tercera edad con la tecnología. Este aspecto cobra especial relevancia debido a la escritura y publicación del volumen durante la crisis pandémica provocada por el covid-19, la cual ha sumido en el aislamiento a muchas personas mayores que han necesitado actualizar sus modos de relacionarse. Tanto los personajes ficcionales de Grace y Frankie como las yayas de La Resistencia demuestran que la ancianidad no está reñida con saber comunicarse usando las nuevas tecnologías. Los abuelos youtubers e influencers descritos en el capítulo 5 van más allá, creando contenido para las redes. El capítulo 9, escrito por Miguel Ángel Pérez Gómez, recalca la necesidad de las empresas de telecomunicaciones de tomar en cuenta a las generaciones mayores como clientes. Finalmente, el capítulo 7, escrito por Francisco Javier López Rodríguez e Irene Raya Bravo, presenta ancianos jugadores de videojuegos cuyas historias se han hecho famosas en redes y en prensa especializada, rompiendo de nuevo el estereotipo de que los mayores no saben "usar las maquinitas".

Uno de los aspectos más relevantes de esta obra es su carácter transmedial. Al final de cada capítulo, encontramos un enlace que nos lleva al programa La isla etaria, emitido en la radio de la Universidad de Sevilla. Cada 
episodio del programa contiene un resumen del capítulo que le corresponde, además de una ampliación con entrevistas a personas mayores que aportan su punto de vista sobre el tema a tratar. Estas entrevistas, que quizás no tienen el rigor académico para ser incluidas en las investigaciones que han dado lugar al libro, sí aportan nuevo contenido y un acercamiento más tangible a la problemática de las personas envejecientes.

Si es posible encontrar alguna limitación al volumen, esta es quizás la repetición de algunos conceptos a lo largo del libro. En la mitad de los capítulos que componen en el libro se nos define el edadismo como concepto y en dos de ellos se utiliza la misma cita de Susan Sontag para definir el doble estándar de envejecimiento entre hombres y mujeres. Además, la crítica a la representación de la tercera edad como segunda juventud se repite en las secciones dedicadas a la radio, las series de ficción, el cine y la tecnología. Sin embargo, podríamos decir que estas son las bases teóricas sobre las que se fundamenta el discurso del libro, por lo que su aparición en varias ocasiones es relevante para esclarecer conceptos.

Por otro lado, en algunos casos, la muestra analizada para explicar la representación de los mayores en los medios resulta un poco anecdótica. El capítulo 4, dedicado a La Yaya's Week de La Resistencia se presenta como un hecho aislado, sin mayor repercusión en el papel de las mujeres envejecientes en la televisión de entretenimiento. Asimismo, el análisis de los ancianos gamers aporta cuatro ejemplos y no presenta un panorama donde podamos encontrar más casos. No ocurre lo mismo en el capítulo dedicado a los mayores youtubers; este capítulo ofrece una visión amplia, aporta varios ejemplos y deja claro que existen más, aunque no se las analice en profundidad en el capítulo.

A pesar de todo, es este un volumen necesario, que da visibilidad a un colectivo frecuentemente ignorado por los medios de comunicación o tratado de manera paternalista y poco respetuosa. Los diversos artículos de $L a$ isla etaria demuestran que la mejor manera de romper estereotipos y prejuicios es representando de manera realista a las personas envejecientes, un grupo social cada vez más numeroso en la sociedad actual. 